\title{
Osteogenesis imperfecta type III: mutations in the type I collagen structural genes, COL1A1 and COL1A2, are not necessarily responsible
}

Gillian A Wallis, Bryan Sykes, Peter H Byers, Christopher G Mathew, Denis Viljoen, Peter Beighton
Department of Biochemistry and Molecular Biology, University of Manchester, Stopford Building, Oxford Road, Manchester M13 9PT, UK. G A Wallis

University of Oxford, Institute of Molecular Medicine, John Radcliffe Hospital, Headington, Oxford OX3 9DU, UK.

B Sykes

Division of Medical and Molecular Genetics, Paediatric Research Unit, Guy's Hospital, London SE1 9RT, UK. $C$ G Mathew

Department of Pathology, University of Washington, Seattle, WA 98195 , USA.

P H Byers

Department of Human Genetics, Medical School, University of Cape Town, Observatory 7925, South Africa. P Beighton D Viljoen

Correspondence to Dr Wallis.

Received 12 November 1992 Revised version accepted 16 December 1992.

\begin{abstract}
Most forms of osteogenesis imperfecta are caused by dominant mutations in either of the two genes, COL1A1 and COL1A2, that encode the proal(I) and proa2(I) chains of type I collagen, respectively. However, a severe, autosomal recessive form of OI type III with a comparatively high frequency has been recognised in the black populations of southern Africa. We performed linkage analyses in eight OI type III families using RFLPs associated with the $C O L 1 A 1$ and $C O L 1 A 2$ loci to determine whether mutations in the genes for type I collagen were responsible for this form of $O I$. Recombination between the OI phenotype and polymorphic markers at both loci was shown in three of the eight families investigated. The combined lod scores for the eight families were $-\mathbf{1 0 . 6}$ for COL1A1 and $-11 \cdot 2$ for COL1A2. Further, we examined the type I procollagen produced by skin fibroblast cultures derived from 15 affected and 12 unaffected subjects from the above eight families plus one further family. We found no evidence for defects in the synthesis, structure, secretion, or posttranslational modification of the chains of type I procollagen produced by any of the family members. These results suggest that mutations within or near the type I collagen structural genes are not responsible for this form of $O I$.

(f Med Genet 1993;30:492-6)
\end{abstract}

Osteogenesis imperfecta (OI) is currently subclassified into four major groups and several subtypes on the basis of clinical and genealogical data. ${ }^{12}$ According to the original classification by Sillence et al, ${ }^{1}$ OI type III is characterised by a severe propensity to fracturing, marked short stature, progressive deformities, and white sclerae and, as the phenotype occurred sporadically, new dominant mutation or autosomal recessive inheritance was postulated. Subsequently, Sillence $e t a l^{3}$ identified seven families in a review of 345 pedigrees of different types of OI where the OI type III phenotype appeared to have an autosomal recessive mode of transmission. There is now accumulating evidence that the OI type III phenotype most often results from dominant mutations in either of the two genes that encode the pro $\alpha 1(\mathrm{I})$ and pro $\alpha 2(\mathrm{I})$ chains
(COL1A1 and COL1A2, respectively) of type I collagen. ${ }^{411}$ In only one instance has a defect in the genes for type I collagen been shown to cause a recessive form of OI type III. ${ }^{12-14}$ In a further family postulated to have a recessive form of OI type III, linkage studies have excluded the involvement of the type I collagen genes. ${ }^{15}$

In contrast to world wide figures, an autosomal recessive (AR) form of OI type III is comparatively common in the black population of southern Africa, where more than 70 affected persons have been studied. ${ }^{16-18}$ In general, recessive inheritance of this condition has been inferred on the basis of recurrence of the defined phenotype in sibs born to unaffected parents and the frequency of the phenotype. We performed linkage analysis and examined collagen synthesis and secretion in skin fibroblast cultures to determine whether mutations in the genes for type I collagen were responsible for this form of OI in southern African patients.

\section{Patients and methods}

PATIENTS

The patients and relatives who participated in this study had been examined previously and were derived from reported series of affected persons in southern Africa. ${ }^{16-19}$ On the basis of genealogical, phenotypic, and radiological criteria the affected subjects were classified as having an AR form of OI type III. The pedigrees are shown in the figure. Apart from family 1 who were of mixed ancestry (African Negro origin with Scottish and Indian admixture), ${ }^{19}$ all the participants were from the black populations of southern Africa. All affected subjects had severe dwarfism, multiple fractures, and marked skeletal deformity owing to bone malleability. The sclerae were white, or in younger children had a slight blue tinge, and dentinogenesis imperfecta was variable. Considerable intrafamilial variability of these latter features was recognised and so they were not considered to be indicative of syndromic heterogeneity. ${ }^{18}$ Families 1 to 7 were selected for study as there was more than one affected subject born to normal parents. Families 8 and 9 were included in the study as, although the condition occurred sporadically in these families, the phenotype of the affected subjects was indistinguishable from the familial condition. In all instances, the parents of affected subjects were normal. 


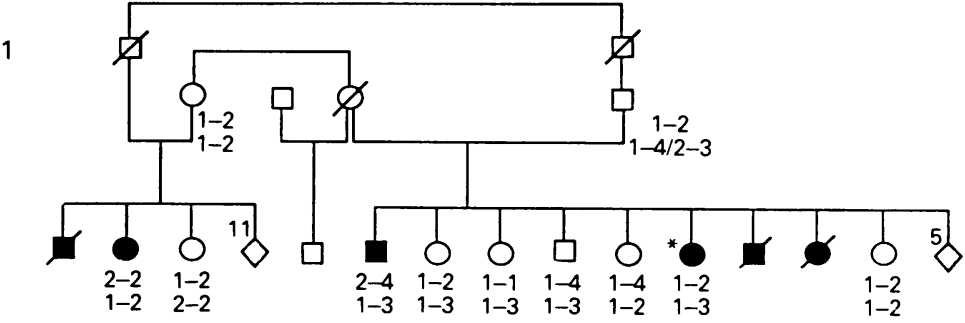

2

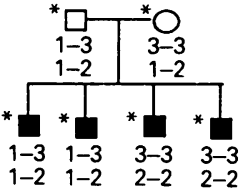

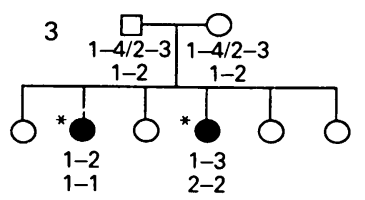

4

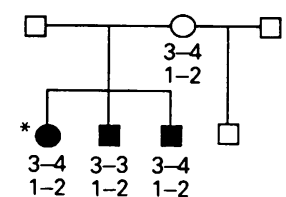

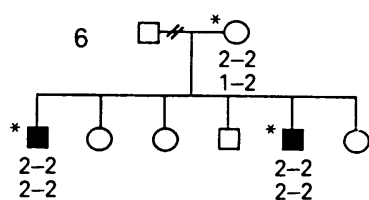

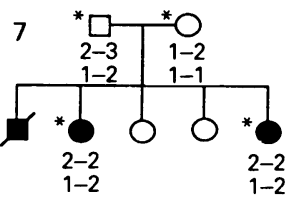

8

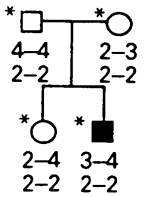

9

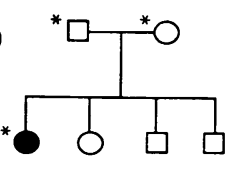

Pedigrees showing COL1A1 (upper) and COL1A2 (lower) genotypes. The haplotypes at each locus were constructed according to the notation in table 1. Genotypes separated by a slash indicate indistinguishable alternative haplotypes. The asterisks indicate subjects from whom skin biopsies were obtained for analysis of their type I procollagen synthesis.
Table 1 Haplotype notation. Combinations of variants used to assemble haplotypes are shown.

\begin{tabular}{lccc}
\hline & Haplotype & RsaI & MspI \\
\hline COL1A1 & 1 & + & + \\
& 2 & + & - \\
& 3 & - & + \\
\hline COL1A2 & 4 & EcoRI & MspI \\
& 1 & + & + \\
& 3 & - & + \\
& 4 & + & - \\
\hline
\end{tabular}

+ and - indicate the presence or absence of the restriction enzyme cleavage sites, respectively. Haplotype notation is that used to construct the genotypes in the figure.

PREPARATION AND ELECTROPHORETIC ANALYSIS OF PROCOLLAGENS AND COLLAGENS

Skin biopsies were taken from those subjects indicated in the figure by an asterisk and used to establish dermal fibroblast cell cultures. Dermal fibroblasts from unrelated, healthy subjects served as controls. Cell cultures were maintained under standard conditions in Dulbecco-Vogt Modified Eagle Medium (DMEM, Irvine Scientific) as previously described. ${ }^{30}$ Labelling of proteins with $2,3,4,5-$ $\left[{ }^{3} \mathrm{H}\right]$ proline $(101 \mathrm{Ci} / \mathrm{mmol}$, Amersham), harvesting of the medium and cell layer proteins, pepsin digestion of the procollagens to yield the collagen chains, and sodium dodecyl sulphate-polyacrylamide gel electrophoresis (SDS-PAGE) were carried out as previously described. ${ }^{30-32}$

The COL1A1 and COL1A2 genotypes were established using previously described restriction site dimorphisms. ${ }^{20-22}$ DNA was prepared from blood samples from all available family members and the samples were genotyped for the presence of the COL1A1 and COL1A2 dimorphisms using Southern blot hybridisation $^{23}$ or the polymerase chain reaction (PCR). ${ }^{24}$ Two RFLPs for MspI and RsaI restriction sites were used as markers for COL1A1. ${ }^{22}$ Genotypes for each dimorphism were detected by Southern blot hybridisation using the probes pIAIHI7526 (MspI) and p2FC.6 (RsaI). ${ }^{22}$ RFLPs for the restriction enzymes $E c o \mathrm{RI}^{20}$ and $M s p \mathrm{I}^{21}$ were used as markers for COL1A2. Two contiguous EcoRI genomic clones NJ-3' and NJ-3"20 were used to detect the EcoRI RFLP and a $4 \mathrm{~kb} E c o$ RI genomic clone ${ }^{2526}$ to detect the MspI RFLP. The RsaI RFLP associated with the COL1A2 gene was not used in this study as it has not been detected in black southern African populations. ${ }^{27}$ The oligonucleotide primers used to amplify across the variable restriction sites in the COL1A1 and COL1A2 genes and the conditions of the PCR reactions were as previously described. ${ }^{28}$ Available subjects from the families were screened for the presence $(+)$ or absence $(-)$ of the COL1Al and COL1A2 polymorphic restriction sites. Haplotypes were constructed according to the notation in table 1 . Lod scores were calculated at a recombination fraction $(\theta)$ of 0.001 using the MLINK program. ${ }^{29}$ Other values of $\theta$ were not considered since the RFLPs were within or very close to the candidate genes.

\section{Results}

LINKAGE ANALYSES OF FAMILIES WITH OI TYPE III

The pedigrees of the OI type III families studied are shown in the figure. The genotypes for the COL1A1 and COL1A2 associated RFLPs are indicated on the pedigrees and the lod scores at $\theta=0.001$ are given in table 2. A lod score was not calculated for family 9 as a DNA sample was available from only one of the sibs. Recombination between the OI phenotype and polymorphic markers at both loci was shown in three of the eight families investigated. In the remaining families, small positive lod scores were obtained at one or both of the loci. However, the combined lod scores for the eight families were -10.6 for $C O L 1 A 1$ and $-11 \cdot 2$ for COL1A2.

Table 2 Lod scores at each locus for each pedigree.

\begin{tabular}{lcc}
\hline Pedigree & COL1A1 & COL1A2 \\
\hline 1 & $-3 \cdot 2$ & -1.9 \\
2 & -4.8 & -4.0 \\
3 & $-2 \cdot 1$ & -4.8 \\
4 & $-2 \cdot 0$ & +0.8 \\
5 & +0.6 & $-2 \cdot 1$ \\
6 & +0.2 & +0.5 \\
7 & +0.6 & +0.3 \\
8 & $+0 \cdot 1$ & 0 \\
9 & $\mathrm{ND}$ & $\mathrm{ND}$ \\
Total & $-10 \cdot 6$ & -11.2 \\
\hline
\end{tabular}

Lod scores were calculated at a value of $\theta=0.001$. A lod score was not calculated (ND) for pedigree 9 as a DNA sample was available from only one of the sibs. 
SCREENING FOR TYPE I COLLAGEN DEFECTS

Methods routinely used in the diagnosis of $\mathrm{OI}^{32}$ were used to examine the type I procollagen produced by the dermal fibroblast cultures established from affected subjects and their unaffected relatives. Examples of defects that have been identified using these methods have been previously published and show their efficacy. ${ }^{4-6}$ In all instances, the type I procollagen and collagen synthesised by the cell cultures migrated normally relative to that of controls, the ratios of the $\alpha 1(\mathrm{I})$ to $\alpha 2(\mathrm{I})$ collagen chains were normal, there was no intracellular retention of the chains, and there was no evidence for increased post-translational overmodification of the chains (results not shown).

\section{Discussion}

As a result of biochemical, molecular genetic, and linkage studies it is now evident that $\mathrm{OI}$ is in most instances caused by heterozygosity for mutations in one of the genes, COL1Al or COL1A2, which respectively encode the $\operatorname{pro} \alpha 1(\mathrm{I})$ and $\operatorname{pro} \alpha 2(\mathrm{I})$ chains of the type I collagen molecule. ${ }^{43-35}$ In OI type III, biochemical studies are compatible with the presence of new dominant mutations that affect the structure of type I procollagen. ${ }^{4-11}$ Alterations to the structure of the type I procollagen molecule can in general be detected on PAGE gels as the procollagen chains are overmodified and poorly secreted. ${ }^{4}$ Molecular studies have shown heterozygosity for point mutations in both COL1A1 (gly526 to cys, ${ }^{5}$ gly415 to cys, ${ }^{9}$ gly844 to ser, ${ }^{8}$ gly 1009 to ser, ${ }^{10}$ and gly 154 to $\arg ^{6}$ ) and COL1A2 (gly259 to cys ${ }^{7}$ ) that result in the substitution of triple helical glycine residues for other amino acids and cause forms of OI type III.

Despite the evidence for dominant mutations causing OI, recurrence of the phenotype in offspring born to phenotypically normal parents does occur. For the perinatal lethal form of $\mathrm{OI}$ (OI type II) the sib recurrence rate is about $6 \%{ }^{36}$ and, in all families investigated, the mechanism of inheritance has been explained by parental gonadal, and often somatic, mosaicism for the mutant allele. ${ }^{37-39}$ In OI type III there is evidence that both recessive inheritance and gonadal mosaicism may be responsible for recurrence of the phenotype. Evidence for recessive inheritance has relied mostly on family studies. ${ }^{3}$ In a consanguineous pedigree in which a severe form of OI segregated as an autosomal recessive trait, a lack of linkage to both COL1A1 and COL1A2 was shown..$^{15}$ In only one instance has homozygosity for a mutation in a gene for type I collagen been proven to cause a recessive form of OI type III..$^{12-14}$ Germline mosaicism for a type I collagen mutation has been reported in three families with autosomal dominant (AD) OI type III. ${ }^{3739}$ As $\mathrm{AD}$ OI type II and $\mathrm{AD}$ OI type III are caused by similar molecular mechanisms (both result predominantly from single base pair changes leading to the substitution of triple helical glycines by other amino acids) it is likely that, with further investigation, the frequency of recurrence of OI type
III resulting from germline mosaicism will compare with that of OI type II. In the form of OI type III identified in the black population of southern Africa, AR inheritance of the condition has been proposed on the basis of the occurrence of multiple affected sibships with normal parents (recurrence of the phenotype has been recorded in 17 of the 44 families investigated), the defined phenotype, and the high frequency of this severe form of OI in this ethnic group. ${ }^{1718}$ In addition, in the previously reported family of mixed ancestry with a similar form of OI, subjects were affected in two branches of the same family. ${ }^{19}$ As the frequency of recurrence of OI type III in the black population is far greater than the apparent frequency of recurrence in other populations, it seems unlikely that gonadal mosaicism is the mechanism responsible for the recurrent phenotype in all families.

We examined the type I collagen produced by skin fibroblast cultures derived from 15 affected and 12 unaffected subjects from nine black southern African families with the AR form of OI type III and in no instance were defects in the synthesis, structure, secretion, and post-translational modification of the composite chains detected. The absence of increased post-translational modification (increased lysyl hydroxylation and hydroxylysyl glycosylation) is significant as this secondary abnormality is a useful marker for the presence of subtle mutation altering the integrity of the collagen helix and the extent of overmodification along the $\alpha$ chains of type I collagen has been used to localise mutations. ${ }^{5040}$ On the basis of these results alone it would not be possible to exclude the involvement of type I collagen defects confidently in all families. In $16 \%$ of cell strains from subjects clinically diagnosed as having OI type III, Wenstrup et $a l^{4}$ were unable to identify alterations in electrophoretic mobility of the chains of type I collagen synthesised. The reason for this may be that point mutations towards the amino-terminal end of the triple helix are difficult to detect owing to the paucity of potentially hydroxylatable lysyl residues. ${ }^{6}$ Alternatively, structural alterations may exist that affect molecular interactions or other aspects of the biological behaviour of type $I$ collagen molecules without modification although no such mutations have as yet been identified. So, it is possible that somatic or germinal mosaicism for mutations within one of the type I collagen genes may cause recurrence of OI type III but in order for this mechanism to explain the frequency of recurrence of OI type III in the black population of southern Africa we would have to postulate that in each instance a new dominant mutation had occurred that did not alter the electrophoretic mobility or secretion of the type I procollagen chains and that the frequency of these kinds of mutations was greater in this population than has been recorded for other populations.

The existence of autosomal recessive pedigrees allows a limited amount of linkage analysis using DNA polymorphisms associated with 
both COL1A1 and COL1A2. A lack of linkage can be inferred if affected sibs do not share the same genotypes and this evidence provides a positive means for excluding the collagen genes as the site of the mutations. In three of the families with OI type III that we investigated, there was discordance between the phenotype and markers at both loci suggesting that a mutation within or near the type I collagen genes are not responsible for OI in these families. The concordant segregation with one or both of the COL1A1 or COL1A2 alleles that was evident in some families may be because of chance as the families were small. Further, this concordant segregation was not associated with the presence of any detectable protein abnormalities.

From phenotypic and genealogical data, OI type III in the southern African black population appears to be homogeneous. Proof of molecular homogeneity within this group, however, requires the elucidation of the cause of the bone fragility, deformity, and disturbance of growth in these patients. It is possible that genes controlling type I collagen processing or maturation might be involved. Equally, abnormalities in connective tissue components other than collagen could cause bone fragility and the bone specific, non-collagenous matrix proteins are possible candidates. ${ }^{41}$ Finding alternative causes for the OI phenotype may assist in the systematic exploration of the pathway between a mutation in one of the collagen genes and the phenotype and could lead to the identification of factors that modify the resultant phenotype.

We are grateful to Kathy Braun, Laura Suesserman, and Sue Schultz for technical assistance. We thank Dr Andrew Read of St Mary's Hospital, Manchester, for his assistance in calculating the lod scores. This work was supported in Cape Town by grants from the Medical Research Council of South Africa, the University of Cape Town Staff Research Fund, the Mauerberger Foundation, and the Harry Crossley Foundation, and in Seattle by grants from the National Institutes of Health (AR 21559), a Clinical Research Grant from the March of Dimes Birth Defects Foundation (6-298), and the Michael Giesman Memorial Fellowship from the Osteogenesis Imperfecta Foundation.

1 Sillence DO, Senn A, Danks DM. Genetic heterogeneity in osteogenesis imperfecta. F Med Genet 1979;16:101-16.

2 Byers PH. Disorders of collagen biosynthesis and structure. In: Scriver CR, Beaudet AL, Sly WS, Valle D, eds. The metabolic basis of inherited disease. 6th ed. New York: McGraw-Hill, 1989:2805-42.

3 Sillence DO, Barlow KK, Cole WG, Dietrich S, Garber AP, Rimoin DL. Osteogenesis imperfecta type III: delineation of the phenotype with reference to genetic
heterogeneity. Am $\mathcal{F}$ Med Genet 1986;23:821-32.

4 Wenstrup RJ, Willing MC, Starman BJ, Byers PH. Molecular basis of clinical heterogeneity in nonlethal variants of osteogenesis imperfecta: distinct biochemical phenotypes predict clinical severity. Am $\mathcal{f}$ Hum Genet 1990;46:975-82.

5 Starman BJ, Eyre D, Charbonneau H, et al. Osteogenesis imperfecta: the position of substitution for glycine by cysteine in the triple helical domain of the pro $\alpha 1(\mathrm{I})$ chains cysteine in the triple helical domain of the pro $\alpha 1(\mathrm{I})$ chains
of type I collagen determines clinical phenotype. $\boldsymbol{f}$ Clin Invest 1989;84:1206-14.

6 Pruchno CJ, Cohn DH, Wallis GA, et al. Osteogenesis imperfecta due to recurrent point mutations at $\mathrm{CpG}$ dinucleotides in the COL1A1 gene of type I collagen. Hum Genet 1991;87:33-40.
7 Wenstrup RJ, Shrago-Howe AW, Lever LW, Phillips CL, Byers PH, Cohn DH. The effects of different cysteine for gyers PH, Cohn DH. The effects of different cysteine for glycine substitutions within $\alpha 2(\mathrm{I})$ chains: evidence of
distinct structural domains within the type I collagen distinct structural domains within the type
triple helix. $\mathcal{F}$ Biol Chem 1991;266:2590-4.

8 Pack M, Constantinou CD, Kalia K, Nielsen KB, Prockop DJ. Substitution of serine for $\alpha \mathrm{l}(\mathrm{I})$-glycine 844 in severe variant of osteogenesis imperfecta minimally destabilizes the triple helix of type I procollagen. $\mathcal{F}$ Biol Chem 1989;264:19694-9.

9 Nicholls AC, Oliver J, Renouf D, Pope FM. Type I collagen mutation in osteogenesis imperfecta and inherited osteoporosis. Fourth International Conference on Osteogenesis Imperfecta, Pavia, Italy, 9-12 September 1990. Abstract, 1990:48.

10 Cohn DH, Wallis G, Zhang X, Byers PH. Serine for glycine substitutions in the $\alpha 1$ (I) chain of type I collagen: biological plasticity in the gly-pro-hyp clamp at the carboxylterminal end of the triple helical domain. Matrix 1990;10:236.

11 Molyneux K, Byers PH, Dalgleish R. A new mutation in the $\alpha 2(\mathrm{I})$ gene of a patient with non-lethal osteogenesis imperfecta. Fourth International Conference on Osteogenesis Imperfecta, Pavia, Italy, 9-12 September 1990 Abstract, 1990:19.

12 Deak SB, Nicholls AC, Pope FM, Prockop DJ. The molecular defect in a non-lethal variant of osteogenesis imperfecta. $\mathcal{F}$ Biol Chem 1983;258:15192-7.

13 Pihlajaniemi T, Dickson LA, Deak S, et al. Osteogenesis imperfecta: cloning of a pro 2 2(I) collagen gene with a frameshift mutation. $\mathcal{F}$ Biol Chem 1984;264:19694-9.

14 Nicholls AC, Osse G, Schloon HG, et al. The clinical features of homozygous $\alpha 2(\mathrm{I})$ collagen deficient osteogenesis imperfecta. $\mathcal{F}$ Med Genet 1984;21:257-62.

15 Aitchison K, Ogilvie D, Honeyman M, Thompson E, Sykes B. Homozygous osteogenesis imperfecta unlinked to collagen I genes. Hum Genet 1988;78:233-6.

16 Beighton P, Spranger J, Versfeld G. Skeletal complications in osteogenesis imperfecta. A review of 153 South African patients. S Afr Med f 1983;64:656-8.

17 Beighton $P$, Versfeld $G$. On the paradoxically high relative prevalence of osteogenesis imperfecta type III in the black population of South Africa. Clin Genet 1985;27:398-401.

18 Viljoen D, Beighton P. Osteogenesis imperfecta type III: an ancient mutation in Africa? $A m \mathcal{F}$ Med Genet 1987;27:907-12.

19 Horan F, Beighton P. Autosomal recessive inheritance of osteogenesis imperfecta. Clin Genet 1975;9:107-11.

20 Tsipouras P, Myers JC, Ramirez F, Prockop DJ. Restriction fragment length polymorphism associated with the
tipouras $P$, Myers JC, Ramirez F, Prockop DJ. Restricpro $\alpha 2$ (I) gene of human type I procollagen. $\mathcal{f}$ Clin Invest 1983;72:1262-7.

21 Grobler-Rabie AF, Brebner DK, Vandenplas S, et al. Polymorphism of DNA sequence in the human proa $2(\mathbf{I})$ collagen gene. $\mathcal{f}$ Med Genet 1985;22:182-6.

22 Sykes BC, Ogilvie DJ, Wordsworth BP, Anderson DJ, Jones N. Osteogenesis imperfecta is linked to both type collagen structural genes. Lancet 1986;ii:69-72.

23 Vandenplas S, Wiid I, Grobler-Rabie A, et al. Blot hybridisation analysis of genomic DNA. F Med Genet 1984;21:164-72.

24 Saiki RK, Gelfand DH, Stoffel S, et al. Primer directed enzymatic amplification of DNA with a thermostable enzymatic amplification of DNA with a the

25 Dalgleish R, Trapnell BC, Crystal RG, Tolstoshev P. Copy number of a human type I $\alpha 2$ collagen gene. $\mathcal{f} \mathrm{Biol}$ Chem 1982;257:13816-22.

26 Tajima S, Ting JPY, Pinnell SR, Kaufman RE. Isolation and characterization of a human pro $\alpha 2(I)$ collagen gen segment. $\mathcal{F}$ Invest Dermatol 1984;82:265-9.

27 Grobler-Rabie AF, Wallis G, Brebner DK, Beighton P Mathew CG. Detection of a high frequency RsaI polymorphism associated with the pro $\alpha 2(\mathrm{I})$ collagen which is linked to an autosomal dominant form of gene genesis imperfecta. EMBO $₹$ 1985;4:1745-8.

28 Baker JL, Lynch J, Priestley L, Sykes B. PCR detection of five restriction site dimorphisms at the type I collagen loci COL1A1 and COL1A2. Nucleic Acids Res 1991;19:4315.

29 Lathrop GM, Lalouel JM. Easy calculations of lod scores and genetic risks on small computers. Am f Hum Genet 1984;36:460-5.

30 Bonadio J, Holbrook KA, Gelinas RE, Jacob J, Byers PH. Altered triple helical structure of type I procollagen in lethal perinatal osteogenesis imperfecta. $\mathcal{f} \mathrm{Biol}$ Chem 1985;260:1734-42.

31 Barsh GS, Byers PH. Reduced secretion of structurally abnormal type I procollagen in a form of osteogenesis imperfecta. Proc Natl Acad Sci USA 1981;78:5142-6.

$32 \mathrm{Cohn}$ DH, Byers PH. Clinical screening for collagen defects in connective tissue diseases. Clin Perinatol 1990;17:739809.

33 Byers PH, Tsipouras P, Bonadio JF, Starman BJ, Schwartz RC. Perinatal lethal osteogenesis imperfecta (OI type II): a biochemically heterogeneous disorder usually due to new mutations in the genes for type I collagen. Am $\mathcal{F}$ Hum

34 Sykes BC, Ogilvie DJ, Wordsworth BP, et al. Consistent linkage of dominantly inherited osteogenesis imperfecta to the type I collagen loci: COL1A1 and COL1A2. Am $\mathcal{J}$ to the type I collagen loci: COL
Hum Gent 1990;46:293-307.

35 Byers PH, Wallis GA, Willing MC. Osteogenesis imperfecta: translation of mutation to phenotype. $\mathcal{F}$ Med Genet 1991;28:433-42.

36 Cohn DH, Starman BJ, Blumberg B, Byers PH. Recurrence 
of lethal osteogenesis imperfecta due to parental mosaicism for a dominant mutation in a human type I collagen

37 Cohn DH, Wallis GA, Edwards MJ, Starman BJ, Byers PH. Germline and somatic mosaicism in osteogenesis imperfecta. Fourth International Conference on Osteogenesis Imperfecta, Pavia, Italy, 9-12 September 1990 Abstract, 1990:47.

38 Wallis GA, Starman BJ, Zinn AB, Byers PH. Variable expression of osteogenesis imperfecta in a nuclear family is explained by somatic mosaicism for a lethal point mutation in the $\alpha 1(\mathrm{I})$ gene COL1Al of type I collagen in a parent. Am F Hum Genet 1990;46:1034-40.
39 Cohen-Solal L, Bonaventure J, Maroteaux P. Dominant mutations in familial lethal and severe osteogenesis imperfecta. Hum Genet 1991;87:297-301.

40 Bateman JF, Chan D, Walker ID, Rogers JG, Cole WG. Lethal perinatal osteogenesis imperfecta due to substitution of arginine for glycine at residue 664 in the collagen $\alpha 1(\mathrm{I})$ chains of type I collagen. $f$ Biol Chem 1987;262:7021-7.

41 Sandberg MM. Matrix in cartilage and bone development: current views on the function and regulation of major organic components. Ann Med 1991;23:207-17. 